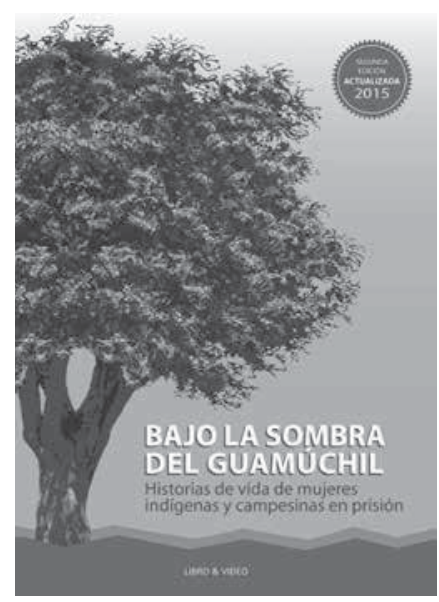

- Bajo la sombra del guamúchil.

Historias de vida de mujeres indígenas

y campesinas en prisión

Rosalva Aída Hernández Castillo

(COORD.), 2A. ED., 2015

Centro de Investigaciones y Estudios

Superiores en Antropología Social/

International Work Group for Indigenous

Affairs, México

\title{
Las historias del guamúchil: prisión y construcción de comunidad
}

\author{
CAROLINA ROBLEDO SILVESTRE
}

Guamuchil Stories: Confinement and Community Building

CARolina Robledo Silvestre Centro de Investigaciones y Estudios Superiores en Antropología Social-Ciudad de México,

Ciudad de México, México carolina.robledo@ciesas.edu.mx

Desacatos 54, mayo-agosto 2017, pp. 195-198

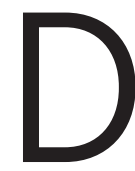

espués de leer Bajo la sombra del guamúchil, uno puede imaginarse la silueta de este árbol, descrito por Amatista Lee como un sobreviviente de las crueldades y un testigo mudo de las injusticias. Erigido en medio del concreto del Centro de Readaptación Social Femenil de Morelos, el guamúchil da sombra a las conversaciones y los sueños que se tejen en el espacio de encierro en el que nace este libro.

Amatista es una de las mujeres en condición de encierro que han formado parte del proyecto de investigación colaborativa coordinado por la antropóloga Rosalva Aída Hernández Castillo, entre cuyos resultados se encuentra esta obra, publicada por el Centro de Investigaciones y Estudios Superiores en Antropología Social (CIESAS) y el International Working Group for Indigenous Affairs (IWGIA).

El libro comienza con el poema Ya no canta para mí la noche, de Galia - también en prisión-, cuyo matiz lírico indica que el documento que el lector tiene entre sus manos no es común para ser el resultado de una investigación académica. Además de poemas, el libro 
ofrece fotografías, ideogramas chinos dibujados por las internas y un video elaborado con una sensibilidad estética especial, que recoge entrevistas con las protagonistas que han recuperado su libertad. A estas producciones se suma la realización de una serie radiofónica que reúne las historias de estas mujeres, disponible de manera gratuita en internet.

La producción de este material fue posible gracias al trabajo interdisciplinario colectivo en el que participaron profesionales comprometidas con una causa común: "sacudir la indiferencia de la sociedad ante la injusticia que se vive cotidianamente en los penales" (p. 285). Justamente, la producción de materiales alternativos ha permitido superar las barreras del lenguaje académico para contrarrestar el silencio que se cierne sobre las historias de las internas, al llevarlas a otros espacios de divulgación.

Rosalva Aída aclara que esta apertura en los lenguajes es el resultado de las formas híbridas y novedosas que fueron adquiriendo las historias de vida en el proceso de construcción entre las investigadoras y las internas. Los orígenes de este proceso, según comenta, se remontan a su interés académico por conocer las condiciones de las mujeres indígenas en prisión. En este camino, se encontró con la escritora Elena de Hoyos, quien llevaba a cabo un taller de escritura desde por lo menos un año atrás con algunas internas que tenían algún grado de escolaridad, ninguna de ellas indígena.

Las mismas mujeres que participaban en este grupo propusieron a la antropóloga escribir la historia de sus compañeras indígenas. Así tomó forma el taller, el cual tenía como objetivo "capacitar a las participantes en la técnica de elaboración de historias de vida, como un recurso literario y de reflexión sobre las desigualdades de género" (p. 18), y como principio, la capacidad transformadora del arte y su posibilidad de expiación del dolor y la vergüenza (p. 286).

La dinámica de los talleres permitió abrir un diálogo intercultural entre las mujeres indígenas y mestizas, animado por la antropóloga, con el propósito de "promover la reflexión crítica en torno a las cadenas de desigualdades étnicas, genéricas y de clase que posibilitaron su reclusión" (p. 18). Estas teorizaciones, que se construyeron de manera colaborativa entre las profesionales y las internas, se revelan en cada historia de vida, gracias a la reflexión de sus protagonistas sobre temas clave, como el sexismo, el racismo y la discriminación, expuestos por medio de un ejercicio de introspección e interacción con los otros.

Después de una apertura inspiradora para un lector curioso de metodologías frescas y novedosas, empiezan las historias de vida de 13 mujeres indígenas y/o campesinas presas. Cada una abre la puerta de su vida íntima para que el lector sea testigo del dolor experimentado desde la infancia y su continuidad a lo largo del tiempo en episodios de violencia, pobreza y marginación. Las emociones juegan un papel esencial en estas historias, que van desde los paisajes rurales y urbanos de la periferia hasta la cárcel, pasan por los espacios familiares, comunitarios y laborales, en los que se revela el más hondo sufrimiento, y a la vez, se describen las más potentes estrategias de supervivencia.

En cada biografía se exponen las representaciones de las internas sobre la mismidad y la otredad, en un ejercicio que busca superar las numerosas contradicciones que se les presentan como mujeres cuando tratan de tomar la palabra o acceder a cualquier tipo de autorrepresentación, no sólo desde la escritura, sino también desde el ejercicio de organizarse y trabajar de manera colectiva. En este ejercicio radica la contribución ética y política del proyecto de investigación que sustenta el libro y que logra consolidar un espacio de solidaridad en el que es posible romper los silencios y las barreras impuestas no sólo por la cárcel, sino por la acumulación de múltiples formas de violencia contra las mujeres y entre las mujeres.

Además de las teorizaciones que atraviesan las historias, éstas plantean un análisis crítico sobre el 
sistema actual de justicia en México, no sólo para aquellas que han sido injustamente apresadas, "sino para todos los que estamos afuera [y] que corremos el peligro de caer en sus 'garras' en cualquier momento" (p. 15). En este sentido, el libro promueve una revisión de las políticas públicas en materia de seguridad y de sus efectos en la libertad de los ciudadanos más vulnerables, e invita a pensar en la lucha contra el crimen organizado como una excusa que ha servido para encarcelar de manera injusta a las poblaciones más marginadas de la sociedad mexicana, sectores que de por sí han sido acorralados por un sistema neoliberal con efectos perversos.

Las 13 historias de vida que recoge el libro no son privativas de quienes las protagonizan, sino un "ejemplo de las múltiples historias de violencia sexual, racismo, discriminación y violencia de Estado que comparten muchas de las 16632 mujeres que se encuentran presas en los 604 centros de reclusión existentes en México" (p. 17).

La compilación de biografías responde a los principios del método biográfico, que tiene como propósito exponer el despliegue, movimiento y operación del mundo social en las vidas individuales. Las biografías de las internas actúan como un tipo de anudamiento de un conjunto de relaciones de poder que se expresan por medio de la violencia, pero también de la resistencia de sus protagonistas. Son historias que no se remiten al pasado ni a lo individual, sino que plantean reflexiones sobre el presente y el futuro de poblaciones enteras que han sido marginadas y criminalizadas en el contexto actual mexicano, e incluso latinoamericano.

La coordinadora del libro describe la experiencia del trabajo de campo en la cárcel como un ejercicio extremo de aprendizaje mutuo, que hace posible la búsqueda de un bien común a partir de la construcción de teorizaciones desde abajo y la puesta en marcha de una red de solidaridad que vence los muros de la prisión. Muestra de ello es la Colectiva Editorial Mujeres en la Sombra, nacida de estos encuentros y que ha publicado más de diez libros, que se suman a éste, como resultado del trabajo comenzado en 2010.

Junto con esta valiosa producción editorial, el proceso de aprendizaje mutuo tuvo consecuencias favorables para las internas, como en el caso de Leo Zavaleta, quien aprendió a leer y escribir para contar su propia historia, y además de colaborar con las ediciones colectivas, publicó su propio libro: "Leo encontró en la escritura una manera de recuperar las fuerzas para seguir, ante múltiples adversidades que enfrentó aún después de haber recuperado la libertad" (p. 291).

Este caso permite ver cómo las limitaciones físicas y morales que impone el encierro son también una posibilidad para la autorreflexión y la palabra, para la búsqueda de sentido vital y la explosión de la creatividad, y muestra cómo la academia puede comprometerse con estos procesos que, aunque no atentan contra el sistema penitenciario ni lo desestabilizan (p. 23), crean fisuras en las formas establecidas que marginan y silencian a sus víctimas. No es extraño que Amatista Lee haya descubierto junto a Noche Buena, otra de las protagonistas del libro, la magia de sentirse libre entre las rejas, cuando conjuraron por medio de la palabra un alivio para la soledad y el encierro.

La potencia de estas palabras nacidas en prisión radica en su carácter sincero y en su mirada profunda, lo que da como resultado un libro conmovedor y desgarrador. El lector de Bajo la sombra del guamúchil disfrutará de una lectura amena y podrá imaginar los paisajes de infancia en los que crecieron las internas en pueblos de Guerrero, Morelos, Chiapas, Puebla y Veracruz; sentir los sonidos del tsotsil, el náhuatl y el tlapaneco con el que arrullaban a sus hijos, el aroma del café colándose por las ventanas, la lluvia cayendo sobre la milpa, el olor de la leña recién puesta, y conocer de cerca la nostalgia de lo que pudo haber sido, la soledad del encierro, la esperanza y la vida misma. 
Grandes escritores en lengua española han pasado parte de su vida en prisión. Entre ellos, el mexicano José Revueltas, que escribió sus dos obras más reconocidas mientras pagaba su condena: Los muros de agua y El apando. Después de sus años de encierro, Revueltas señaló que la experiencia de la cárcel le había mostrado las relaciones humanas en su desnudez más completa: "la cárcel tiene esa virtud. Desnuda al hombre” (Ruiz, 1992: 74). Añadimos: desnuda a la mujer. Esta desnudez es la del cuerpo femenino disciplinado, despreciado y castigado, pero también rebelde y obstinado en vivir.

Bajo la sombra del guamúchil es una obra esencial para los científicos sociales que deseen promover investigaciones colaborativas y explorar nuevos lenguajes y formatos de divulgación, en especial para aquellos que se comprometen con el trabajo que puede crear fisuras en los muros de la opresión. D

\section{Bibliografía}

Revueltas, José, 1978 [1941], Los muros de agua, Era, México.

—_, 1982, El apando, Era, México.

Ruiz Abreu, Álvaro, 1992, José Revueltas: los muros de la utopía, Cal y Arena, México. 